\title{
Measuring Public Opinion in U.S. Metro Areas, 2006-2016
}

\author{
Andrew M. Lindner \\ Department of Sociology \\ Skidmore College \\ Saratoga Springs, NY
}

February 15, 2018

\begin{abstract}
While a great many state-level longitudinal measures of public opinion are now available, few measures exist at the Metropolitan Statistical Area (MSA) level. I demonstrate a method for estimating public opinion annually in the fifty-three largest MSAs via disaggregation from the Cooperative Congressional Election Study (CCES). Using this method, I construct an MSA-level citizen political ideology measure from 2006 through 2016. This measure is strongly correlated with MSA-level results from the Presidential Elections in 2008, 2012, and 2016. While the MSA ideology scale itself has many potential applications for future research, so, too, does the underlying method of estimating MSA-level measures using CCES data.
\end{abstract}




\section{Introduction}

From the Georg Simmel to Jane Jacobs, metropolitan areas and the role they play in shaping individuals' lives have long been a great source of interest to sociologists, political scientists, and urban studies scholars alike. In the $21^{\text {st }}$ century, with increasing urbanization, a greater proportion of Americans live within the social radius of a city (Massey and Tannen 2017). Moreover, as national politics have been mired in partisan gridlock in recent years, some have argued that cities and politicians have taken on new importance (Barber 2013).

Metropolitan areas are, perhaps, more important than ever as a subject for social scientific study. And, yet, we lack reliable, longitudinal measures of public opinion in the largest U.S. Metropolitan Statistical Areas (MSAs). An MSA refers to the set of counties surrounding an urbanized core of at least 50,000 people that have "a high degree of social and economic integration with the core as measured through commuting ties" (U.S. Census Bureau 2010). Studies examining social dynamics in metro areas often examine a single year, sample a small numbers of MSAs, or simply do not include measures of political attitudes (Claassen and Gibson 2018; Ferranna, Gerolimetto, and Magrini 2016; Howe et al. 2015).

By contrast, researchers seeking to study U.S. states have developed a variety of methods to create annual longitudinal estimates. Researchers, like Erikson, Wright, and Mclver (2007), have used disaggregation from multiple years of national polls to generate state-level estimates of public opinion. Another approach, employing multilevel regression, imputation, and post-stratification methods (known as MRP), addresses issues of small samples in small states and the under-representation of respondents outside MSAs and generates annual, longitudinal state-level measures (Park, Gelman, and Bafumi 2004; Pacheco 2011). In recent years, national surveys with extremely large sample sizes $(30,000+$ respondents) like the Cooperative Congressional Election Study (CCES), which was introduced in 2006, have allowed researchers to more easily disaggregate data to the state-level. There are now so many state-level measures of political attitudes and behavior that there is a "one-stop shop" with over nine-hundred variables (Jordan and Grossmann 2016).

At present, we lack datasets longitudinally tracking public opinion in the largest MSAs. While Presidential and midterm election results in MSAs can be used as an indicator of public opinion, there are several problems with this approach. First, they conflate public opinion with political behavior. Elections only "sample" those who turn out to vote, giving researchers a measure of voter opinion, but not the broader public opinion. Second, the size and composition of midterm and Presidential elections tend to be quite different, making for an apples-to-oranges comparison (Fowler and Smirnov 2005). What is needed then in order to better understand the dynamics of MSAs is a disaggregation approach that parallels previous state-level work in order to estimate public opinion in large MSAs.

This research note demonstrates how survey responses from the CCES, weighted with information about the demographic composition of metro areas from the American Community Survey (ACS), can be disaggregated to create MSA-level measures of public opinion since 2006. As an example, I construct a measure of MSA citizen ideology for fifty-three metro areas from 2006-2016 and compare it with data from Presidential elections in the same period. 


\section{Methods}

The MSA ideology scale introduced here was constructed using data from the Common Content portion of the CCES and, for the purpose of case weighting, the ACS. The Common Content portion of the CCES is an annual nationally representative survey, administered online by YouGov. In election years, the sample is collected in pre- and post-election waves and the sample has ranged from 32,800 to 64,600 respondents. ${ }^{1}$ In addition to demographic, behavioral, and attitudinal measures, the CCES records a series of geographic variables for each respondent, including their home county and the associated Federal Information Processing Standards (FIPS) code. Though the CCES does not include MSA as a variable, MSAs are constructed from groups of counties. ${ }^{2}$ A dataset listing counties within MSAs is available from the U.S. Bureau of Economic Analysis (https://www.bea.gov/regional/docs/msalist.cfm?mlist=45). By merging an MSA variable with CCES data, it is possible to identify respondents' MSAs.

Given the CCES's large overall sample size, in most years, there are at least fifty-three U.S. MSAs with a minimum of 100 respondents. Major metro areas like New York, Chicago, and Los Angeles typically have over a thousand CCES respondents in a given year. These samples are sufficient to render MSA-level estimates of a survey measure with a reasonable degree of confidence.

Table 1 presents the sample size and maximum estimated sampling error with a $95 \%$ level of confidence for the top fifty-three MSAs in the U.S. in each year of the election year CCES. ${ }^{3}$ Twenty-eight of the cities have estimated sampling errors of less than $5 \%$ in most years of the survey. Admittedly, the relatively modest sample size for cities like Dayton Beach, FL and Birmingham, AL (especially in the earlier years of the CCES) mean that any MSA-level estimate produced is subject to a higher degree of error. However, even these cities tend to have maximum estimated sampling errors of less than $10 \%$.

\section{[TABLE 1 ABOUT HERE]}

While a portion of the CCES questions change from year to year, the Common Content consists of approximately 60 questions, which are included on all surveys. Future researchers can substitute in any Common Content measure of their choice, allowing for a wide range of applications. Here, I use the CCES's 5-point ideology scale as an example of how the CCES can be used to construct MSA-level estimates. This ideology variable is measured as follows:

\footnotetext{
${ }^{1}$ Non-election year samples, which are, collected in a single wave, typically include fewer than 15,000 respondents. As a result, the non-election year CCES surveys have too few responses in most MSAs to produce stable metro area estimates and are, therefore, not used in the current project.

${ }^{2}$ The first few years of the CCES include a Designated Media Market variable. However, this measure tends to be inclusive of respondents farther from the urban core than MSA.

${ }^{3}$ The sampling error for a proportion was calculated with the formula $1.96 * \sqrt{\frac{\hat{p}(1-\hat{p})}{n}}$ where $\hat{\mathrm{p}}=.5$ in order to allow for the maximum estimated sampling error.
} 
"In general, how would you describe your own political viewpoint?"

$1 \quad$ Very liberal

$2 \quad$ Liberal

$3 \quad$ Moderate

4 Conservative

$5 \quad$ Very conservative

$6 \quad$ Not sure

$8 \quad$ Skipped

Cases with missing data (6 and 8 ) on the ideology were dropped from the sample.

To aggregate these individual-level survey responses into MSA-level estimates, I merged each case with ACS 5-year data on the demographic composition of each respondent's MSA. ${ }^{4}$ Then, I constructed case-weights for the CCES respondents by race, age, and education to better reflect the MSA's actual demographic composition. ${ }^{5}$ In most cases, the CCES sample was a higher proportion white, more highly educated, and older than the MSA. Then, using the CCES participants' response to the ideology measure, I estimated a weighted mean for each of the 53 MSAs in each year of the CCES. Finally, for the non-election years, I interpolated ideology scores by taking the mean of the prior and following year.

The resulting measure represents the mean ideology of people in a given metro area in a given year, not the actual distribution of all people in those MSAs. Thus, both an MSA where all people were moderates (3s) and a highly polarized MSA with an equal number of "Very Liberal" (1) and "Very Conservative" people would have a mean of 3. The MSA ideology scale ranged from 2.45 (San Francisco, CA in 2008) to 3.56 (Birmingham, AL in 2008).

The dataset of MSA-level ideology by year (2006-2016) is available at OSF (https://osf.io/n53ad/). To assess the validity of the MSA ideology scale, I merged it with MSA-level Presidential Election results from 2008, 2012, and 2016 and compared the relationship between the Democratic vote share in each MSA and the Democratic vote share. See Table 2 for complete descriptive statistics.

[TABLE 2 ABOUT HERE]

\section{Results}

Figure 1 presents a kernel density plot of the distribution of ideology across MSAs and time. The distribution is fairly normally distributed around a mean of 3.013 ("Moderate") with a slight right-skew. Also notable is that the range is fairly compressed, varying only from somewhere between "Liberal" and "Moderate" to somewhere between "Conservative" and "Moderate." Very few MSAs in the aggregate are particularly radical one way or the other.

\footnotetext{
${ }^{4}$ Full Stata code available at Open Science Framework (OSF): https://osf.io/n53ad/.

${ }^{5}$ Race was weighted by the MSA proportion of white, black, and other residents. Education was weighted by the proportion of no high school, less than college degree, and college degree holders in the MSA. Age was weighted by the MSA proportion in three groups: under 35 years old, 35-64, and 65 and older.
} 
[FIGURE 1 ABOUT HERE]

Nonetheless, the MSAs tend to match what we might intuitively expect. Metro areas with liberal reputations like San Francisco, Austin, Los Angeles, and Boston appear in the lowest quartile of MSA ideology scores, while more conservative cities like Birmingham, Nashville, Oklahoma City, and San Antonio are in the highest quartile. Figure 2 plots all fiftythree MSAs over time (the gray lines). The blue line is a smoothed trend line, showing that the mean ideology in MSAs became more conservative between 2008 and 2010 and then grew gradually more liberal through 2016 .

[FIGURE 2 ABOUT HERE]

As an initial test of the validity of the MSA ideology scale, the ideology scores from Presidential Election years were compared with the MSA's Democratic vote share. As seen in Figure 3, there is a strong negative correlation between MSA ideology and Democratic vote share in all three years. The pooled correlation for all three election years is -.694 ( $\mathrm{p}<.0001)$. As we would expect, metro areas with a higher ideology score (more conservative), Democratic Presidential candidates tend to receive a smaller share of all votes. These results offer some evidence that the MSA ideology scale is measuring what it intends to measure.

\section{[FIGURE 3 ABOUT HERE]}

\section{Discussion}

This paper aims to make two contributions. First, I introduce an MSA-level measure of citizen ideology, which appears to have validity when compared to election results. Second, the MSA ideology scale offers an example of the broader method of combining measures from the Common Content section of the CCES and the demographic data from ACS to create MSAlevel measures. I briefly discuss how each might be extended.

Future research ought to further confirm the validity of the MSA ideology scale, perhaps with comparisons in the small number of metro areas where there has been some consistently polling. While such confirmatory research is necessary, the MSA ideology scale has a wide variety of applications. It will be used as either an independent variable (e.g., how is MSA ideology associated with the crime rate?) or dependent variable (e.g., what factors are associated with changes in MSA ideology?) in MSA-level studies. The MSA ideology scale might also be used as a contextual control or interaction variable in individual-level studies.

As future research is conducted, researchers must make reasonable decisions about which MSA-years have too small of a sample to render a valid estimate. For this application, I have chosen to err on the side of including more MSAs. However, some researchers may choose to use only the top 25 MSAs, excluding those with larger estimated sampling errors.

Of course, mean ideology is only one potential measure that can be constructed using this method. Interested in the standard deviation of ideology in MSAs? Want a different 
variable altogether? Prefer a different set of weighting variables from the ACS? A wide variety of applications is possible with very slight modifications to the Stata code.

In conclusion, MSAs are an increasingly important unit of analysis for political and social scientific researchers. This research note demonstrates how MSA-level estimates of public opinion can be constructed via disaggregation from the CCES. 


\section{References}

Barber, Benjamin R. 2013. If Mayors Ruled the World: Dysfunctional Nations, Rising Cities. New Haven, CT: Yale University Press.

Claassen, Christopher, and James L. Gibson. 2018. "Does Intolerance Dampen Dissent? MacroTolerance and Protest in American Metropolitan Areas." Political Behavior, 1-21. doi:https://doi.org/10.1007/s11109-018-9444-x.

Erikson, Robert S., Gerald C. Wright, and John P. Mclver. 2007. "Measuring the Public's Ideological Preferences in the 50 States: Survey Responses versusRoll Call Data." State Politics \& Policy Quarterly 7 (2): 141-51.

Ferranna, Licia, Margherita Gerolimetto, and Stefano Magrini. 2016. "The Evolution of Income Disparities across US Metropolitan Statistical Areas." Working Papers. https://ideas.repec.org/p/ven/wpaper/201625.html.

Fowler, James H., and Oleg Smirnov. 2005. "Dynamic Parties and Social Turnout: An AgentBased Model." American Journal of Sociology 110 (4): 1070-94. doi:10.1086/426554.

Howe, Peter D., Matto Mildenberger, Jennifer R. Marlon, and Anthony Leiserowitz. 2015. "Geographic Variation in Opinions on Climate Change at State and Local Scales in the USA." Nature Climate Change 5 (6): 596-603. doi:10.1038/nclimate2583.

Jordan, Marty P., and Matt Grossmann. 2016. "The Correlates of State Policy Project v.1.10." East Lansing, MI.

Massey, Douglas S., and Jonathan Tannen. 2017. "Suburbanization and Segregation in the United States: 1970-2010." Ethnic and Racial Studies 86 (4): 1-18.

Pacheco, Julianna. 2011. "Using National Surveys to Measure Dynamic U.S. State Public Opinion: A Guidline for Scholars and an Application." State Politics \& Policy Quarterly 11 (4): 415-39.

Park, David K., Andrew Gelman, and Joseph Bafumi. 2004. "Bayesian Multilevel Estimation with Poststratification: State-Level Estimates from National Polls." Political Analysis 12 (4): 375-85. doi:10.1093/pan/mph024.

U.S. Census Bureau. 2010. "Geographic Terms and Concepts." 


\begin{tabular}{|c|c|c|c|c|c|c|c|c|c|c|c|c|}
\hline \multirow[b]{2}{*}{ MSA } & \multicolumn{6}{|c|}{ Sample size in MSA } & \multicolumn{6}{|c|}{ Sampling Error (95\% Confidence Level) } \\
\hline & 2006 & 2008 & 2010 & 2012 & 2014 & 2016 & 2006 & 2008 & 2010 & 2012 & 2014 & 2016 \\
\hline New York-Newark-Jersey City, NY-NJ-PA & 1513 & 1547 & 2702 & 2714 & 3121 & 4156 & 0.025 & 0.025 & 0.019 & 0.019 & 0.018 & 0.015 \\
\hline Chicago, IL & 1138 & 824 & 1952 & 1610 & 1878 & 2068 & 0.029 & 0.034 & 0.022 & 0.024 & 0.023 & 0.022 \\
\hline Los Angeles, CA & 1062 & 852 & 1826 & 1613 & 1895 & 2041 & 0.030 & 0.034 & 0.023 & 0.024 & 0.023 & 0.022 \\
\hline Philadelphia-Camden-Wilmington, PA-NJ-DE-MD & 663 & 719 & 1162 & 1116 & 1191 & 1426 & 0.038 & 0.037 & 0.029 & 0.029 & 0.028 & 0.026 \\
\hline Dallas, TX & 830 & 627 & 1167 & 1026 & 1085 & 1193 & 0.034 & 0.039 & 0.029 & 0.031 & 0.030 & 0.028 \\
\hline Atlanta, GA & 789 & 524 & 1177 & 1096 & 1077 & 1255 & 0.035 & 0.043 & 0.029 & 0.030 & 0.030 & 0.028 \\
\hline Washington, D.C. & 625 & 493 & 1058 & 1025 & 1035 & 1461 & 0.039 & 0.044 & 0.030 & 0.031 & 0.030 & 0.026 \\
\hline Miami-Fort Lauderdale-West Palm Beach, FL & 559 & 477 & 1056 & 905 & 1000 & 1320 & 0.041 & 0.045 & 0.030 & 0.033 & 0.031 & 0.027 \\
\hline Phoenix, AZ & 610 & 545 & 1018 & 950 & 922 & 984 & 0.040 & 0.042 & 0.031 & 0.032 & 0.032 & 0.031 \\
\hline Houston, TX & 620 & 411 & 866 & 795 & 842 & 1051 & 0.039 & 0.048 & 0.033 & 0.035 & 0.034 & 0.030 \\
\hline Detroit, MI & 749 & 415 & 756 & 747 & 821 & 887 & 0.036 & 0.048 & 0.036 & 0.036 & 0.034 & 0.033 \\
\hline Boston, MA & 417 & 411 & 724 & 818 & 829 & 1032 & 0.048 & 0.048 & 0.036 & 0.034 & 0.034 & 0.031 \\
\hline San Francisco-Oakland, CA & 543 & 396 & 753 & 650 & 682 & 801 & 0.042 & 0.049 & 0.036 & 0.038 & 0.038 & 0.035 \\
\hline Seattle, WA & 564 & 425 & 685 & 722 & 667 & 736 & 0.041 & 0.048 & 0.037 & 0.036 & 0.038 & 0.036 \\
\hline Tampa, FL & 414 & 403 & 750 & 632 & 735 & 863 & 0.048 & 0.049 & 0.036 & 0.039 & 0.036 & 0.033 \\
\hline Minneapolis-St. Paul, MN & 466 & 386 & 644 & 668 & 693 & 731 & 0.045 & 0.050 & 0.039 & 0.038 & 0.037 & 0.036 \\
\hline Riverside-San Bernardino-Ontario, CA & 347 & 305 & 638 & 661 & 667 & 675 & 0.053 & 0.056 & 0.039 & 0.038 & 0.038 & 0.038 \\
\hline Portland, OR & 434 & 324 & 476 & 620 & 569 & 591 & 0.047 & 0.054 & 0.045 & 0.039 & 0.041 & 0.040 \\
\hline St. Louis, MO & 419 & 303 & 591 & 503 & 549 & 567 & 0.048 & 0.056 & 0.040 & 0.044 & 0.042 & 0.041 \\
\hline Pittsburgh, PA & 300 & 380 & 543 & 405 & 500 & 624 & 0.057 & 0.050 & 0.042 & 0.049 & 0.044 & 0.039 \\
\hline Denver, CO & 324 & 289 & 555 & 497 & 535 & 509 & 0.054 & 0.058 & 0.042 & 0.044 & 0.042 & 0.043 \\
\hline San Diego, CA & 339 & 285 & 558 & 453 & 503 & 522 & 0.053 & 0.058 & 0.041 & 0.046 & 0.044 & 0.043 \\
\hline Orlando, FL & 290 & 222 & 524 & 467 & 512 & 637 & 0.058 & 0.066 & 0.043 & 0.045 & 0.043 & 0.039 \\
\hline Baltimore, MD & 318 & 253 & 467 & 497 & 466 & 563 & 0.055 & 0.062 & 0.045 & 0.044 & 0.045 & 0.041 \\
\hline Kansas City, MO-KS & 304 & 297 & 429 & 473 & 416 & 438 & 0.056 & 0.057 & 0.047 & 0.045 & 0.048 & 0.047 \\
\hline Las Vegas, NV & 234 & 266 & 424 & 454 & 438 & 524 & 0.064 & 0.060 & 0.048 & 0.046 & 0.047 & 0.043 \\
\hline Cleveland, $\mathrm{OH}$ & 254 & 225 & 416 & 397 & 512 & 518 & 0.061 & 0.065 & 0.048 & 0.049 & 0.043 & 0.043 \\
\hline Cincinnati, $\mathrm{OH}$ & 251 & 264 & 442 & 356 & 393 & 466 & 0.062 & 0.060 & 0.047 & 0.052 & 0.049 & 0.045 \\
\hline
\end{tabular}

\footnotetext{
${ }^{1}$ MSAs sorted by total sample size across all years of CCES.
} 
Table 1. MSAs by Annual Sample Size and Sampling Error (Cont'd) ${ }^{1}$

\begin{tabular}{|c|c|c|c|c|c|c|c|c|c|c|c|c|}
\hline \multirow[b]{2}{*}{ MSA } & \multicolumn{6}{|c|}{ Sample size in MSA } & \multicolumn{6}{|c|}{ Sampling Error (95\% Confidence Level) } \\
\hline & 2006 & 2008 & 2010 & 2012 & 2014 & 2016 & 2006 & 2008 & 2010 & 2012 & 2014 & 2016 \\
\hline San Antonio, TX & 249 & 213 & 389 & 408 & 386 & 473 & 0.062 & 0.067 & 0.050 & 0.049 & 0.050 & 0.045 \\
\hline Columbus, $\mathrm{OH}$ & 268 & 202 & 417 & 313 & 417 & 463 & 0.060 & 0.069 & 0.048 & 0.055 & 0.048 & 0.046 \\
\hline Charlotte, NC & 218 & 243 & 380 & 389 & 380 & 451 & 0.066 & 0.063 & 0.050 & 0.050 & 0.050 & 0.046 \\
\hline Indianapolis, IN & 277 & 231 & 409 & 320 & 364 & 436 & 0.059 & 0.064 & 0.048 & 0.055 & 0.051 & 0.047 \\
\hline Austin, TX & 286 & 201 & 373 & 338 & 367 & 467 & 0.058 & 0.069 & 0.051 & 0.053 & 0.051 & 0.045 \\
\hline Sacramento, CA & 276 & 181 & 389 & 340 & 368 & 403 & 0.059 & 0.073 & 0.050 & 0.053 & 0.051 & 0.049 \\
\hline Milwaukee, WI & 216 & 155 & 316 & 321 & 326 & 364 & 0.067 & 0.079 & 0.055 & 0.055 & 0.054 & 0.051 \\
\hline Nashville, TN & 223 & 185 & 318 & 290 & 292 & 331 & 0.066 & 0.072 & 0.055 & 0.058 & 0.057 & 0.054 \\
\hline Providence, RI & 167 & 156 & 275 & 359 & 320 & 330 & 0.076 & 0.078 & 0.059 & 0.052 & 0.055 & 0.054 \\
\hline Jacksonville, FL & 172 & 160 & 370 & 268 & 289 & 338 & 0.075 & 0.077 & 0.051 & 0.060 & 0.058 & 0.053 \\
\hline Virginia Beach-Norfolk-Newport News, VA-NC & 147 & 149 & 263 & 313 & 297 & 346 & 0.081 & 0.080 & 0.060 & 0.055 & 0.057 & 0.053 \\
\hline San Jose, CA & 180 & 144 & 280 & 201 & 267 & 340 & 0.073 & 0.082 & 0.059 & 0.069 & 0.060 & 0.053 \\
\hline Rochester, NY & 158 & 143 & 254 & 223 & 257 & 274 & 0.078 & 0.082 & 0.061 & 0.066 & 0.061 & 0.059 \\
\hline Buffalo, NY & 126 & 125 & 225 & 226 & 231 & 316 & 0.087 & 0.088 & 0.065 & 0.065 & 0.064 & 0.055 \\
\hline Raleigh, NC & 126 & 116 & 208 & 227 & 246 & 277 & 0.087 & 0.091 & 0.068 & 0.065 & 0.062 & 0.059 \\
\hline Louisville, KY & 139 & 128 & 237 & 239 & 211 & 240 & 0.083 & 0.087 & 0.064 & 0.063 & 0.067 & 0.063 \\
\hline Oklahoma City, OK & 150 & 159 & 238 & 219 & 183 & 241 & 0.080 & 0.078 & 0.064 & 0.066 & 0.072 & 0.063 \\
\hline Richmond, VA & 152 & 112 & 198 & 226 & 206 & 279 & 0.079 & 0.093 & 0.070 & 0.065 & 0.068 & 0.059 \\
\hline Hartford, CT & 102 & 137 & 256 & 202 & 196 & 229 & 0.097 & 0.084 & 0.061 & 0.069 & 0.070 & 0.065 \\
\hline Salt Lake City, UT & 150 & 111 & 132 & 197 & 183 & 213 & 0.080 & 0.093 & 0.085 & 0.070 & 0.072 & 0.067 \\
\hline New Orleans, LA & 108 & 93 & 189 & 188 & 198 & 195 & 0.094 & 0.102 & 0.071 & 0.071 & 0.070 & 0.070 \\
\hline Memphis, TN & 112 & 105 & 164 & 202 & 186 & 201 & 0.093 & 0.096 & 0.077 & 0.069 & 0.072 & 0.069 \\
\hline Birmingham, AL & 121 & 97 & 193 & 167 & 166 & 201 & 0.089 & 0.100 & 0.071 & 0.076 & 0.076 & 0.069 \\
\hline Daytona Beach, FL & 108 & 81 & 196 & 155 & 163 & 167 & 0.094 & 0.109 & 0.070 & 0.079 & 0.077 & 0.076 \\
\hline
\end{tabular}

${ }^{1}$ MSAs sorted by total sample size across all years of CCES. 
Table 2. Descriptive Statistics

\begin{tabular}{lcccccc}
\hline & $\mathrm{n}$ & Mean & Median & $\begin{array}{c}\text { Standard } \\
\text { Deviation }\end{array}$ & Min & Max \\
\hline MSA ideology scale & 572 & 3.013 & 2.997 & .175 & 2.454 & 3.565 \\
Democratic vote share & 156 & .534 & .525 & .086 & .346 & .774 \\
\hline
\end{tabular}


Figure 1. Ideology Scale Kernel Density Plot

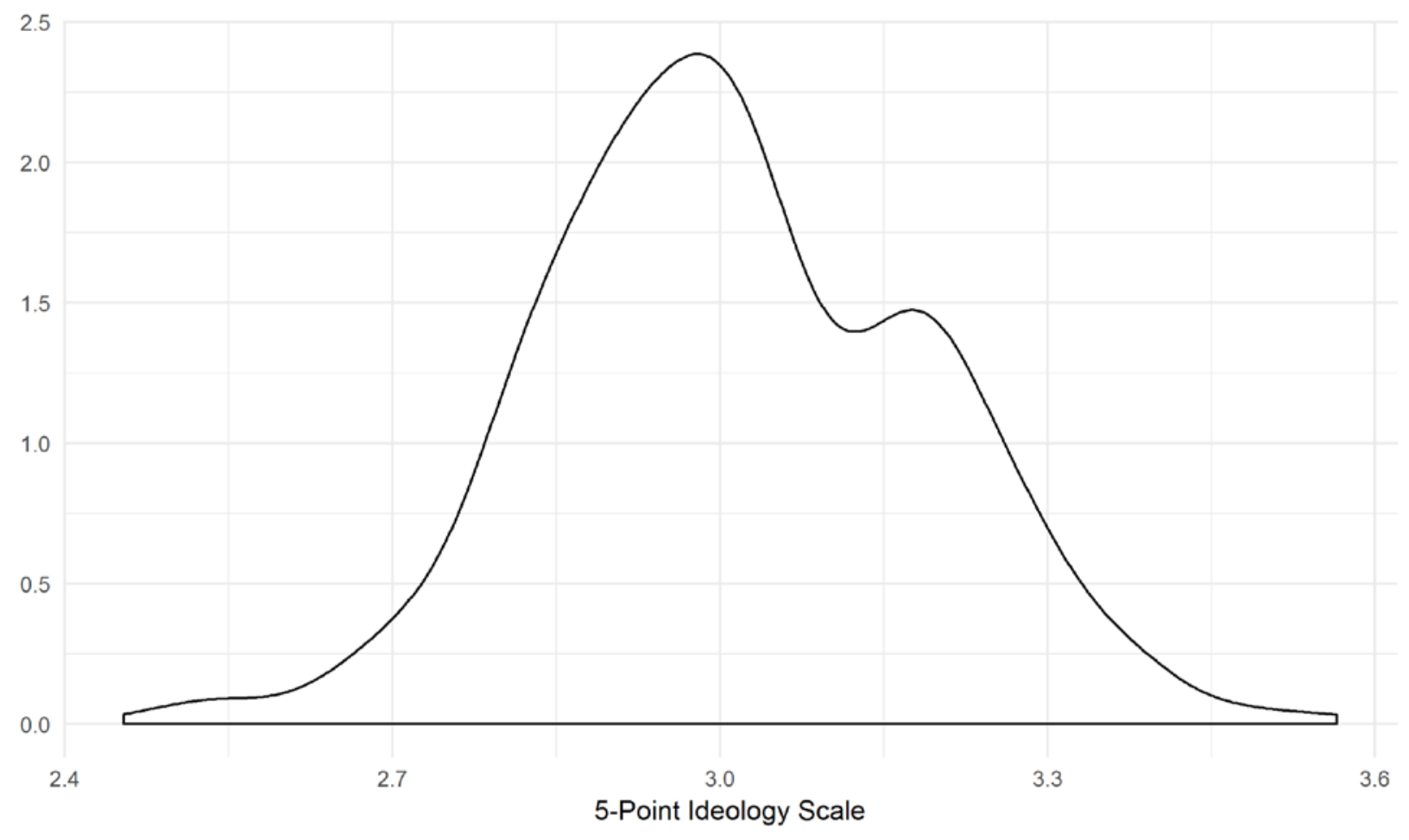


Figure 2. Ideology Over Time in the 53 Largest MSAs

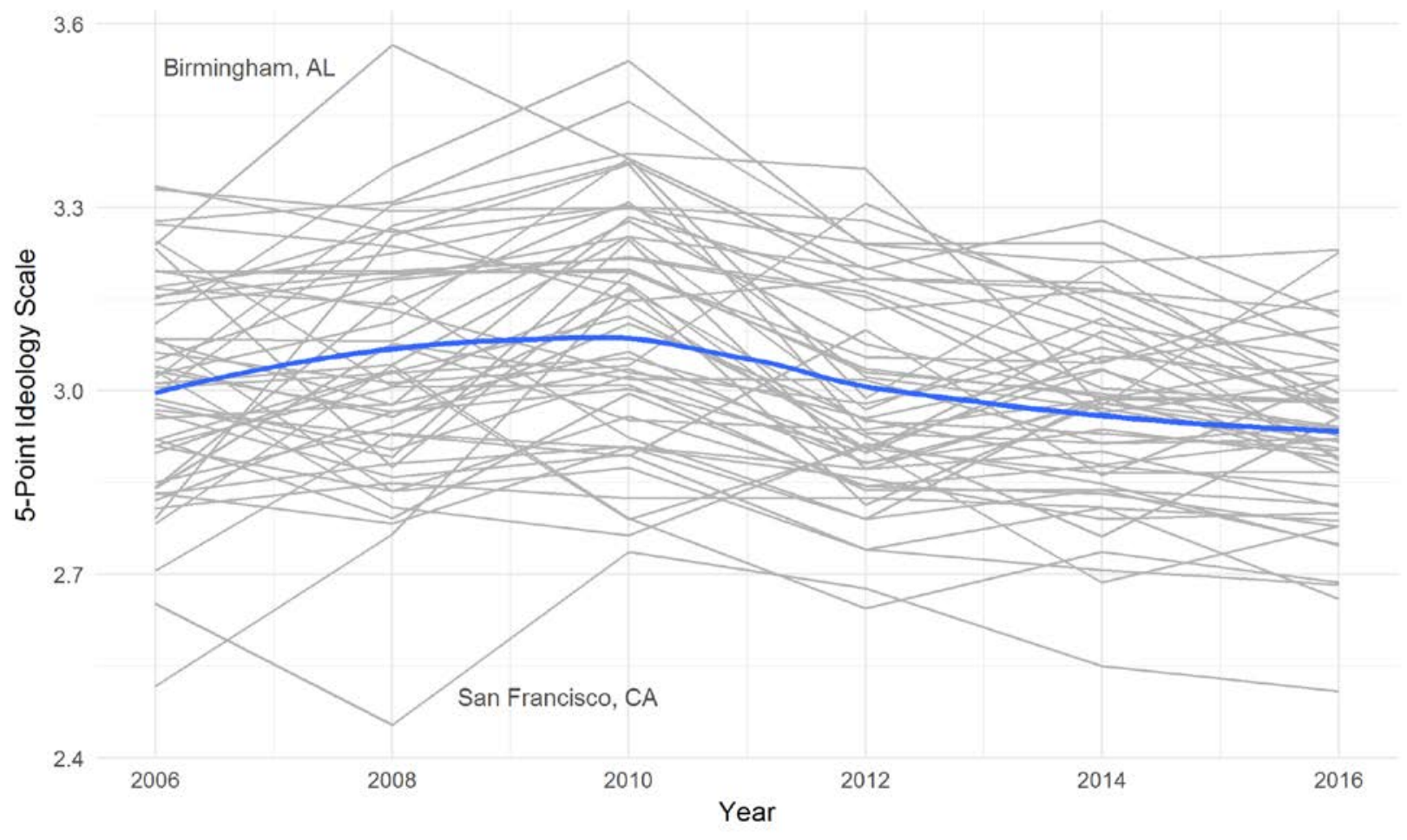


Figure 3. MSA Ideology Scale by Presidential Democratic Vote Share ${ }^{1}$
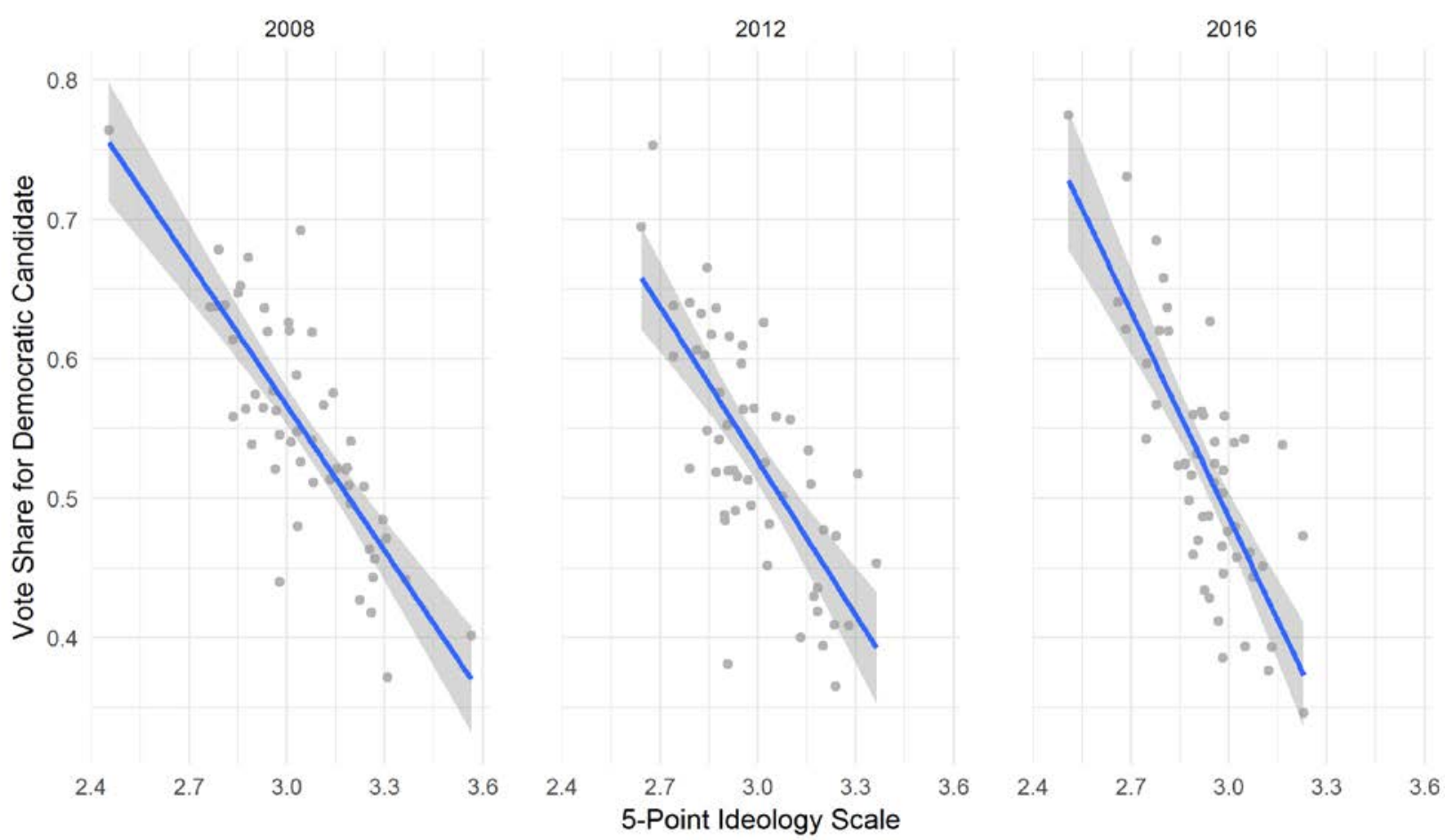

${ }^{1}$ Overall $\mathrm{r}=-.694(\mathrm{p}<.0001)$. 